\title{
Influence of chronic inflammation and autoimmunity on coronary calcifications and myocardial perfusion defects in systemic lupus erythematosus patients
}

\author{
Wojciech Plazak • Mieczyslaw Pasowicz • Magdalena Kostkiewicz • \\ Jakub Podolec $\cdot$ Lidia Tomkiewicz-Pajak · Jacek Musial • Piotr Podolec
}

Received: 4 March 2011/Revised: 23 May 2011/Accepted: 21 June 2011/Published online: 10 July 2011

(C) The Author(s) 2011. This article is published with open access at Springerlink.com

\begin{abstract}
Objective Conventional risk factors for coronary artery disease fail to explain the increased frequency or cardiovascular morbidity in systemic lupus erythematosus (SLE) patients. This study was conducted to determine the possible influence of autoimmune and inflammatory phenomena markers on coronary artery calcifications and myocardial perfusion abnormalities in SLE patients.

Materials and methods Multi-detector computed tomography (MDCT)-based coronary calcium scoring and single photon emission computerized tomography (SPECT) studies (Tc-99m sestamibi) were performed in 60 SLE patients in stable clinical condition, without a prior history of coronary artery disease. Laboratory evaluation included serum C-reactive protein (CRP), complement $\mathrm{C} 3 \mathrm{c}$ and $\mathrm{C} 4$ components and antiphospholipid antibodies (aPL). The latter
\end{abstract}

Responsible Editor: John Di Battista.

W. Plazak $(\bowtie) \cdot$ M. Kostkiewicz $\cdot$ L. Tomkiewicz-Pajak

P. Podolec

Department of Cardiac and Vascular Diseases, The John Paul II

Hospital, Jagiellonian University Medical College,

ul. Pradnicka 80, 31-202 Krakow, Poland

e-mail: wplazak@szpitaljp2.krakow.pl

\section{Pasowicz}

Center for Diagnosis, Prevention and Telemedicine,

The John Paul II Hospital, Jagiellonian University

Medical College, Krakow, Poland

\section{J. Podolec}

Cardiovascular Intervention Center, The John Paul II Hospital,

Jagiellonian University Medical College, Krakow, Poland

\section{J. Musial}

Department of Internal Medicine, Jagiellonian University

Medical College, Krakow, Poland included anticardiolipin (aCL) and anti- $\beta 2$-glycoprotein I (a $\beta 2 \mathrm{GPI})$ antibodies, of both $\mathrm{IgG}$ and $\mathrm{IgM}$ classes, and lupus anticoagulant (LA) in plasma.

Results SPECT revealed persistent perfusion defects in $22(36.7 \%)$ patients and exercise-induced defects in eight $(13.3 \%)$, while MDCT revealed coronary calcifications in $15(25 \%)$. Calcium scores ranged from 1 to 843.2 (mean $113.5 \pm 259.7)$. No association was found between conventional coronary artery disease risk factors (obesity, hypertension, tobacco use, hyperlipidaemia, diabetes) nor $\mathrm{CRP}, \mathrm{C} 3 \mathrm{c}$ or $\mathrm{C} 4$ levels and coronary calcifications or myocardial perfusion defects. On the contrary, in patients with these pathologies, augmented autoimmunization was found, reflected by increased aCL IgG and anti $\beta 2$ GPI IgG levels. In patients with aCL IgG $>20 \mathrm{RU} / \mathrm{ml}$ or anti $\beta 2 \mathrm{GPI}$ $\mathrm{IgG}>3 \mathrm{RU} / \mathrm{ml}$, the relative risk of coronary calcification formation was 4.1 compared to patients with normal values. Accordingly, in LA-positive patients the relative risk of coronary calcification formation was 4.4 compared to LA-negative patients.

Conclusions Conventional risk factors for coronary artery disease as well as markers of an ongoing inflammation did not show any association with perfusion defects and/or coronary artery calcifications in SLE patients. On the contrary, calcified atherosclerotic plaques and myocardial perfusion defects were observed mainly in patients with elevated levels of anticardiolipin and a $\beta 2$ GPI antibodies of the IgG class. It might be speculated that coronary artery calcifications and perfusion defects are a result of antiphospholipid antibodies-induced coronary artery microthrombosis.

Keywords Systemic lupus erythematosus . Autoimmune diseases - Coronary calcification . Atherosclerosis - MDCT $\cdot$ SPECT $\cdot$ Perfusion scintigraphy 


\section{Introduction}

\section{Objectives}

Systemic lupus erythematosus (SLE) is a generalized autoimmune disease, in which a diffuse, chronic inflammatory reaction plays an important etiological role. Nowadays, the mortality of SLE patients is influenced by increased occurrence of severe cardiovascular complications [1].

Conventional risk factors for coronary artery disease (diabetes, hypertension, tobacco use, hyperlipidaemia, sedentary lifestyle) do not explain the increased risk of atherosclerosis and cardiovascular complications in SLE patients [2]. The other possible mechanisms include a generalized, chronic inflammation, reflected by high C-reactive protein (CRP) level. The relation between the increased CRP level and life-threatening cardiovascular episodes is well documented [2]. The other characteristic finding in generalized inflammation is a reduced level of complement system components (mainly C3c and C4).

Beside the chronic inflammation, the second factor that may potentially influence pathologic changes in the arteries is the presence of antiphospholipid antibodies (aPL). Elevated aPL levels are related to an increased risk of thrombosis in the arteries and microcirculation [3-7]. The coexistence of aPL and thrombosis in the above-mentioned vascular beds meets the criteria for the diagnosis of antiphospholipid syndrome [8], which appears in one-third of SLE patients [9].

\section{Aim of the study}

This study was conducted to determine the influence of chronic inflammation and the presence of aPL on coronary artery calcifications and myocardial perfusion abnormalities in SLE patients assessed by multi-detector computed tomography (MDCT)-based coronary calcium scoring and single photon emission computed tomography (SPECT).

\section{Methods}

Inclusion and exclusion criteria

The study was performed in 60 consecutive patients treated for systemic SLE in the Department of Internal Medicine, Jagiellonian University Medical College, Krakow, Poland. All patients fulfilled at least four American College of Rheumatology classification criteria for SLE [10, 11]. Before the study, informed consent was obtained from each patient. The study protocol conforms to the ethical guidelines of the 1975 Declaration of Helsinki. The study was approved by the Ethical Committee of the Jagiellonian University in Krakow.

Inclusion criteria comprised stable clinical conditions of SLE (no need for immunosuppressive therapy intensification, i.e. current immunosuppressive drug dose increase or introduction of an additional immunosuppressive drug within the last 3 months). Exclusion criteria were as follows: prior history of coronary artery disease, known cancer, clinical symptoms of heart failure (NYHA III or IV class), renal failure (creatinine clearance $<30 \mathrm{ml} / \mathrm{min}$ ) and/ or respiratory failure.

Patients studied

In the group of 60 patients examined, 54 (90\%) were females andsix (10\%) males, aged 20-73 years (mean age 51.8 years). The duration of the disease at the time of examination was between 2 and 32 years (mean 15.5 years). Three patients had been previously diagnosed with antiphospholipid syndrome (APS) based on the revised APS classification criteria [8]. One of the three suffered from an objectively confirmed pulmonary embolism. There were two tobacco smokers; none of the patients was obese. The history revealed arterial hypertension in three subjects; there were no diabetic patients. ECG recordings at rest were normal in all the patients. The results of peripheral blood count, serum sodium, potassium, glucose, creatinine and urinalysis were all normal. The distribution of the patients according to their SLEDAI score [12] is shown in Table 1. The main complaints at inclusion were arthralgias and, among laboratory findings, low complement levels and increased ANA titers (see below). The immunosuppressive treatment included methylprednisolone in $32(53.3 \%)$ subjects ( $\leq 4 \mathrm{mg}$ for clinical stability maintenance), prednisone in two $(3.3 \%)$, chloroquine derivate in five $(8.3 \%)$, azathioprine in four $(6.7 \%)$, cyclophosphamide in three $(5 \%)$, and methotrexate in two $(3.3 \%)$. The remaining patients had not used any immunosuppressive drugs in the last 12 months of observation. Other treatment included angiotensin-converting enzyme inhibitors in four $(6.7 \%)$ subjects, betablockers in three $(5 \%)$ and calcium channel blockers in two $(3.3 \%)$. APS patients were treated with anticoagulant (warfarin, two patients) or antiplatelet therapy (aspirin, one patient).

The presence and types of autoantibodies identified in the patients examined as well as the concentrations of CRP and complement $\mathrm{C} 3 \mathrm{c}$ and $\mathrm{C} 4$ components are shown in Table 2. 
Table 1 SLEDAI score in SLE patients at the time of study

\begin{tabular}{lc}
\hline SLEDAI score & Number of patients $(\%)$ \\
\hline 0 & $1(1.7)$ \\
2 & $18(30.0)$ \\
4 & $18(30.0)$ \\
5 & $7(11.7)$ \\
6 & $6(10.0)$ \\
8 & $6(10.0)$ \\
9 & $1(1.7)$ \\
10 & $1(1.7)$ \\
12 & $1(1.7)$ \\
20 & $1(1.7)$ \\
\hline
\end{tabular}

\section{SPECT study}

In all the patients SPECT studies (ECAM Gamma Camera, Siemens, Germany) were performed at rest and during exercise in a 2-day protocol. On the first day, at near maximal stress, a $25-40 \mathrm{mCi}$ dose of Tc-99m sestamibi was injected (the actual dose was modified taking into account the patient's weight) and the exercise was continued forone additional minute after the injection. Tc-99m sestamibi SPECT imaging was begun 15-30 min later. On the second day, rest examinations were performed. SPECT was performed using a circular $180^{\circ}$ acquisition for 60 projections at $20 \mathrm{~s}$ per projection. Myocardial perfusion was assessed in 17 left ventricle myocardial segments. The number of segments with persistent or exercise-induced perfusion defects were assessed visually by analysts blinded to any other information.

\section{Coronary calcium scoring}

Coronary calcium scoring was performed using a multidetector CT imager (Somatom Definition, Siemens, Germany).
The images were ECG-triggered with 3-mm-thick sections obtained covering the whole heart. Coronary artery calcifications were defined as lesions with attenuation greater than $130 \mathrm{HU}$ in more than four adjacent pixels. In order to quantify coronary calcium, 3D Leonardo application (Siemens, Germany) was used. The number of atherosclerotic plaques in particular coronary arteries and their volume were assessed. The Agatson calcium score was calculated [13].

Laboratory tests

Standard laboratory tests were performed. Additionally, the levels of CRP (high-sensitivity) and complement system $\mathrm{C} 3 \mathrm{c}$ and $\mathrm{C} 4$ factors were assessed by nephelometry (Siemens, Germany).

Serum levels of anticardiolipin (aCL) and anti- $\beta 2$-glycoprotein I (a $\beta 2$ GPI) antibodies (of both $\operatorname{IgG}$ and IgM classes) were measured using a home-made ELISA with Sapporo standard for anti $\beta 2$ GPI antibody measurements (HCAL for IgG, EY2C9 for IgM) [9]. The values exceeding the 99th percentile of a healthy population sample were considered positive.

Lupus anticoagulant (LA) determination was performed in accordance with the three-step procedure recommended by the International Society on Thrombosis and Haemostasis [14].

\section{Statistical analysis}

Statistical analysis was performed using Statistica Six Sigma software. All numerical data were expressed as mean values \pm standard deviations or as proportions. Continuous variables were compared using the $t$ test. The chi-square test was used to examine differences in proportions. The level for statistical significance was predetermined at $p<0.05$. To adjust for the confounding

Table 2 Autoantibodies and other laboratory parameters measured in SLE patients studied

\begin{tabular}{|c|c|c|}
\hline & Range (mean $\pm \mathrm{SD}$ ) & $\begin{array}{l}\text { Number of patients with } \\
\text { out-of-range levels (\%) }\end{array}$ \\
\hline $\mathrm{aCL}$ IgG [RU/ml] & $0.68-121.56(14.4 \pm 20.3)$ & $20(33.3)$ \\
\hline $\mathrm{aCL} \operatorname{IgM}[\mathrm{RU} / \mathrm{ml}]$ & $1.62-52.93(12.1 \pm 10.6)$ & $26(43.3)$ \\
\hline $\operatorname{anti} \beta 2 \mathrm{GPI} \mathrm{IgG}[\mathrm{RU} / \mathrm{ml}]$ & $0.16-95.33(3.8 \pm 15.3)$ & $8(13.3)$ \\
\hline $\operatorname{anti} \beta 2 \mathrm{GPI} \operatorname{IgM}[\mathrm{RU} / \mathrm{ml}]$ & $0.14-21.66(2.2 \pm 3.7)$ & $24(40)$ \\
\hline LA & - & $11(18.3)$ \\
\hline ANA [titer] & $0-1 / 20,480$ & $56(93.3)$ \\
\hline $\mathrm{CRP}[\mathrm{mg} / \mathrm{l}]$ & $0.18-41.70(4.16 \pm 7.40)$ & $11(18.3)$ \\
\hline $\mathrm{C} 3 \mathrm{c}[\mathrm{g} / \mathrm{l}]$ & $0.43-1.39(0.90 \pm 0.25)$ & $32(53.3)$ \\
\hline $\mathrm{C} 4[\mathrm{~g} / \mathrm{l}]$ & $0.02-0.26(0.13 \pm 0.05)$ & $16(26.7)$ \\
\hline
\end{tabular}

$a C L$ Anticardiolipin antibodies (cut-off value for IgG $>20 \mathrm{RU} / \mathrm{ml}$, for IgM $>30 \mathrm{RU} / \mathrm{ml}$; see "Methods"), anti $\beta 2 G P I$ anti $\beta 2$-glycoprotein I antibodies (cut-off value for $\mathrm{IgG}>3 \mathrm{RU} / \mathrm{ml}$, for $\mathrm{IgM}>2.6 \mathrm{RU} / \mathrm{ml}$; see "Methods"), $L A$ lupus anticoagulant, $A N A$ antinuclear antibodies, $C R P$ $\mathrm{C}$-reactive protein. Elevated value for $\mathrm{CRP}>5 \mathrm{mg} / \mathrm{l}$. Decreased values for $\mathrm{C} 3 \mathrm{c}<0.9 \mathrm{~g} / \mathrm{l}$, for $\mathrm{C} 4<0.1 \mathrm{~g} / 1$ 
effect of age on SPECT and MDCT results, an ANOVA model was used with age as a covariate.

\section{Results}

In $37(61.6 \%)$ out of 60 patients examined, pathologic results of SPECT or MDCT studies were found. Figure 1 shows examples of coronary calcifications and myocardial perfusion defect observed in a patient with elevated aPL levels.

SPECT study revealed myocardial perfusion abnormalities in $30(50.0 \%)$ patients: persistent defects in 22 $(36.7 \%)$ patients, exercise-induced defects in $8(13.3 \%)$. The distribution of patients according to the number of underperfused myocardial segments of the left ventricle is shown in Table 3 . Out of 30 patients with perfusion

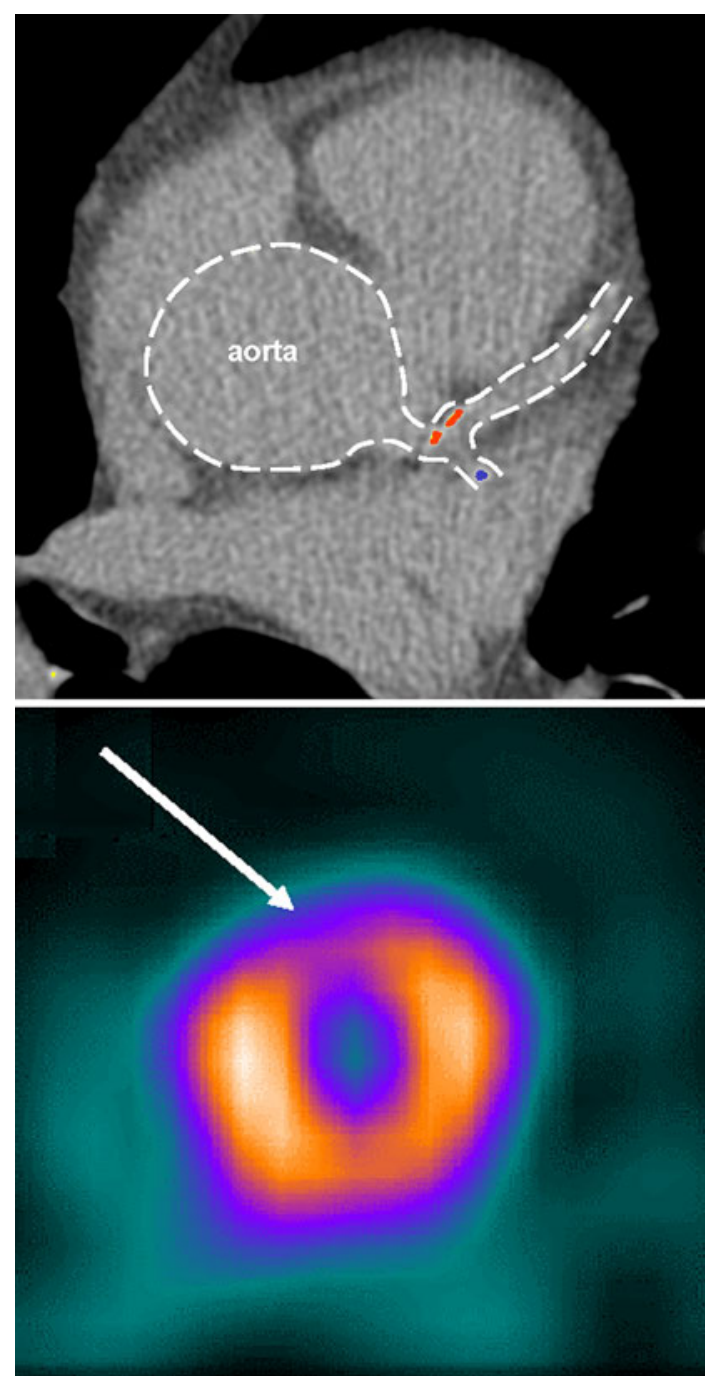

Fig. 1 Examples of MDCT (above) and SPECT (below) results in a patient with elevated aCL IgG $(26.11 \mathrm{RU} / \mathrm{ml})$, elevated anti $\beta 2 \mathrm{GPI}$ $\mathrm{IgG}(3.66 \mathrm{RU} / \mathrm{ml})$ and positive lupus anticoagulant test
Table 3 The distribution of SLE patients according to the number of myocardial segments with perfusion abnormalities in SPECT study

\begin{tabular}{lll}
\hline $\begin{array}{l}\text { Number of segments with } \\
\text { perfusion abnormalities }\end{array}$ & $\begin{array}{l}\text { Persistent } \\
\text { defects }(\%)\end{array}$ & $\begin{array}{l}\text { Exercise-induced } \\
\text { defects }(\%)\end{array}$ \\
\hline 0 & $38(63.3)$ & $52(86.7)$ \\
1 & - & $2(3.3)$ \\
2 & $7(11.7)$ & - \\
3 & $13(21.7)$ & $4(6.7)$ \\
4 & - & $2(3.3)$ \\
5 & $2(3.3)$ & - \\
Total & $60(100)$ & $60(100)$ \\
\hline
\end{tabular}

Table 4 The distribution of SLE patients according to perfusion abnormalities and coronary calcifications in particular coronary arteries

\begin{tabular}{lll}
\hline Coronary arteries & SPECT $(\%)$ & MDCT $(\%)$ \\
\hline LAD & $22(73.3)$ & $8(53.3)$ \\
RCA & $3(10.0)$ & $2(13.3)$ \\
LAD + RCA & $3(10.0)$ & $1(6.7)$ \\
LAD + Cx & $2(6.7)$ & - \\
LAD + Cx + RCA & - & $4(26.7)$ \\
Total & $30(100)$ & $15(100)$ \\
\hline
\end{tabular}

$L A D$ Left anterior descending artery, $R C A$ right coronary artery, $C x$ circumflex artery

abnormalities, in 21 (70\% of this group) classic signs of ischaemia (horizontal or down-slope ST depression $\geq 0.1 \mathrm{mV}$ ) were visible in ECG recordings during exercise.

MDCT revealed coronary calcifications in $15(25 \%)$ patients. The number of atherosclerotic calcified plaques ranged from 1 to 23 (mean $6 \pm 6.9$ ), their volume 2-761.8 $(108.8 \pm 234.2) \mathrm{mm}^{3}$. Calcium scores ranged from 1 to 843.2 (mean $113.5 \pm 259.7$ ).

The distribution of patients according to perfusion abnormalities and coronary calcifications in particular coronary arteries is shown in Table 4.

Myocardial perfusion abnormalities together with the presence of coronary calcifications were present in nine (15\%) patients. In $21(35 \%)$ patients SPECT study was abnormal despite the lack of coronary calcifications (calcium score $=0)$. On the other hand, in six $(10 \%)$ patients with mild calcium deposits [1-3 plaques, calcium score 4.4-35.1 (mean $14.87 \pm 14.24$ )], SPECT study did not show perfusion defects.

We found no influence of conventional risk factors for coronary artery disease (obesity, hypertension, tobacco use, hyperlipidaemia, diabetes) on coronary calcifications formation or myocardial perfusion defects (Tables 5, 6). The generalized inflammation reflected by high CRP and low $\mathrm{C} 3 \mathrm{c}$ and $\mathrm{C} 4$ levels did not significantly result in the presence of atherosclerotic lesions or perfusion disturbances. 
Table 5 Age, glucose and lipid levels, inflammatory and immunologic findings in patients without (calcium score $=0$ ) and with coronary calcifications on MDCT study

$C R P$ C-reactive protein, $a C L$ anticardiolipin antibodies, anti $\beta 2 G P I$ anti $\beta 2$-glycoprotein I antibodies, $L A$ lupus anticoagulant, $A N A$ antinuclear antibodies

$n s$ not significant. Values in bold type are statistically significant

Table 6 Age, glucose and lipid levels, inflammatory and immunologic findings in patients without myocardial perfusion defects and with perfusion defects on SPECT study

$C R P$ C-reactive protein, $a C L$ anticardiolipin antibodies, anti $\beta 2 G P I$ anti $\beta 2$-glycoprotein I antibodies, $L A$ lupus anticoagulant, $A N A$ antinuclear antibodies

ns not significant. Values in bold type are statistically significant

\begin{tabular}{llll}
\hline & Calcium score $=0(n=45)$ & Calcium score $>0(n=15)$ & $p$ \\
\hline Age $($ years $)$ & $\mathbf{3 6 . 0 6} \pm \mathbf{1 1 . 6 1}$ & $\mathbf{4 8 . 5 5} \pm \mathbf{1 1 . 5 6}$ & $<\mathbf{0 . 0 1}$ \\
Total cholesterol $(\mathrm{mmol} / \mathrm{l})$ & $4.93 \pm 1.10$ & $5.0 \pm 1.42$ & $\mathrm{~ns}$ \\
LDL cholesterol $(\mathrm{mmol} / \mathrm{l})$ & $2.51 \pm 0.51$ & $3.10 \pm 1.38$ & $\mathrm{~ns}$ \\
HDL cholesterol $(\mathrm{mmol} / \mathrm{l})$ & $1.23 \pm 0.18$ & $1.38 \pm 0.45$ & $\mathrm{~ns}$ \\
Triglycerides $(\mathrm{mmol} / \mathrm{l})$ & $1.54 \pm 0.06$ & $1.56 \pm 0.74$ & $\mathrm{~ns}$ \\
Glucose $(\mathrm{mmol} / \mathrm{l})$ & $4.73 \pm 0.23$ & $4.0 \pm 0.63$ & $\mathrm{~ns}$ \\
CRP $(\mathrm{mg} / \mathrm{l})$ & $4.48 \pm 8.43$ & $3.23 \pm 3.24$ & $\mathrm{~ns}$ \\
C3c $(\mathrm{g} / \mathrm{l})$ & $0.89 \pm 0.23$ & $0.92 \pm 0.30$ & $\mathrm{~ns}$ \\
$\mathrm{C} 4(\mathrm{~g} / \mathrm{l})$ & $0.14 \pm 0.05$ & $0.11 \pm 0.06$ & $\mathrm{~ns}$ \\
aCL IgG $(\mathrm{RU} / \mathrm{ml})$ & $\mathbf{1 1 . 2} \pm \mathbf{1 0 . 1 0}$ & $\mathbf{2 4 . 7 0} \pm \mathbf{1 5 . 9 1}$ & $<\mathbf{0 . 0 5}$ \\
aCL IgM $(\mathrm{RU} / \mathrm{ml})$ & $11.6 \pm 11.30$ & $13.50 \pm 9.00$ & $\mathrm{~ns}$ \\
anti $\beta 2 \mathrm{GPI} \mathrm{IgG}(\mathrm{RU} / \mathrm{ml})$ & $\mathbf{1 . 3 1} \pm \mathbf{1 . 1 8}$ & $\mathbf{1 1 . 6 1} \pm \mathbf{1 0 . 9 1}$ & $<\mathbf{0 . 0 5}$ \\
anti $\beta 2 \mathrm{GPI} \mathrm{IgM}(\mathrm{RU} / \mathrm{ml})$ & $2.13 \pm 4.10$ & $2.21 \pm 2.23$ & $\mathrm{~ns}$ \\
LA $(n, \%)$ & $\mathbf{3}(\mathbf{6 . 7 \%})$ & $\mathbf{8}(\mathbf{5 3 . 3 \%})$ & $\mathbf{8 3 2 0} \pm \mathbf{4 5 2 1}$ \\
ANA (titer) & $\mathbf{4 6 6 8} \pm \mathbf{2 7 1 7}$ & & $<\mathbf{0 . 0 5}$ \\
\hline
\end{tabular}

On the contrary, regardless of their age, in patients with atherosclerotic plaques in coronary vessels or with myocardial perfusion defects, augmented autoimmunization was found, reflected as increased aCL IgG and anti $\beta 2 \mathrm{GPI}$ IgG levels (Tables 5, 6). Additionally, in patients with coronary calcifications a significantly higher level of antinuclear antibodies and higher frequency of lupus anticoagulant incidence were observed (Table 5).

In all three patients with APS, perfusion defects were observed on SPECT study, and in two of them coronary atherosclerotic plaques were present.

In patients with elevated levels of aCL IgG $>20 \mathrm{RU} / \mathrm{ml}$ or anti $\beta 2 \mathrm{GPI} \mathrm{IgG}>3 \mathrm{RU} / \mathrm{ml}$, the relative risk of coronary calcification formation was 4.1 compared to patients with normal values. Accordingly, in patients positive for lupus anticoagulant, the relative risk of coronary calcification formation was 4.4 compared to LA-negative patients.

\section{Discussion}

The major findings of this study include the association of coronary calcification formation and myocardial perfusion abnormalities in SLE patients with the presence of antiphospholipid antibodies. Neither conventional coronary artery disease risk factors (obesity, hypertension, tobacco use, hyperlipidaemia, diabetes) nor CRP, C3c and C4 
levels revealed a significant influence on these pathologies in the studied population.

Our results support the data previously published showing the high frequency of myocardial perfusion defects in SLE patients $[15,16]$. Perfusion defects were present in $50 \%$ of cases, despite normal rest ECG recordings and lack of myocardial ischaemia clinical symptoms. In most of our patients the number of left ventricle underperfused segments was low (2-3). It has to be stressed, however, that even small perfusion defects in SPECT strongly affect the prognosis in non-SLE populations $[17,18]$. We showed a higher frequency of persistent perfusion abnormalities compared to exercise-induced defects. This might be partially explained by the fact that antiphospholipid antibodies are associated with thrombotic events in coronary microcirculation [19], which is discussed below. Thrombosis in microcirculation might lead to the small persistent perfusion defects observed in our study, whereas exercise-induced defects, usually observed in coronary artery disease, are caused by the presence of atherosclerotic plaques narrowing the epicardial arteries.

Besides the presence of myocardial perfusion abnormalities, $25 \%$ of our asymptomatic SLE patients manifested atherosclerosis in coronary arteries. Coronary vessels are most frequently affected by calcifications; in a recently published study of 50 SLE patients [20], the frequency of atherosclerotic plaques observed in MDCT was highest in coronary arteries ( $42 \%$ of patients with calcifications), followed by carotid arteries ( $24 \%$ of patients with calcifications). In accordance with our findings, a study of 157 SLE patients showed that in young subjects with the mean age of 40 , the frequency of coronary artery calcifications is $30-40 \%$ [21]. This percentage is relatively higher than in the general population: in a study of 35,388 subjects calcium scores $>10$ were observed in only $10 \%$ of cases, and calcium scores $>100$ in 2\% [22]. Coronary calcium deposits provide independent prediction of short- and longterm cardiac events [23-25]. Even in patients with normal SPECT results, the increased coronary calcium score identifies subjects at high long-term cardiac risk [23].

Interestingly, our study did not show an influence of conventional risk factors of coronary artery disease (obesity, hypertension, tobacco use, hyperlipidaemia, diabetes) on coronary calcification formation or myocardial perfusion defects. Moreover, a generalized inflammation reflected by higher CRP and lower $\mathrm{C} 3 \mathrm{c}$ and $\mathrm{C} 4$ concentrations did not significantly result in the presence of atherosclerotic lesions. This may be due to the lack of subjects with severely augmented inflammatory process in our study: in patients with CRP levels $>20 \mathrm{mg} / \mathrm{l}$ its influence on cardiovascular damage was reported [2].

In patients with myocardial perfusion defects or atherosclerotic plaques in coronary vessels, augmented autoimmunization was found, reflected as an increased aCL IgG and anti $\beta 2$ GPI IgG levels. The evidence that antiphospholipid autoantibodies play a role in thrombosis is persuasive [3]. Various studies have suggested that these antibodies may cause thrombosis by activation of endothelial cells or platelets or by inhibition of the protein $\mathrm{C}$ activation pathway [4-7]. Although antiphospholipid antibodies are associated with arterial and venous thrombosis, the extent to which they influence other clinical manifestations is either controversial or uncertain. The data from the literature based on echocardiography suggest its relation to valvular pathology [26], but in other studies no such relation has been found [27]. There are, however, reports showing higher titers of aCL [28] and antiß2GPI [29] antibodies in patients with SLE or MCTD and pulmonary hypertension. It is tempting to speculate that perfusion abnormalities results from thrombi formed in the coronary microcirculation leading to perfusion defects in small regions of myocardium. Such defects, localized predominantly in the segments supplied by the left anterior descending artery, were observed in our study.

The antiphospholipid antibodies may also initiate or exacerbate the process of lipid deposition and plaque formation [30]. Among antiphospholipid antibodies, a crucial role in the pathogenesis of atherosclerosis is attributed to aCL antibodies and anti $\beta 2$ GPI antibodies [31, 32].

Increased levels of antinuclear antibodies in patients with coronary calcifications were also shown in our study. There is little data concerning atherogenesis enhancement by these antibodies. One in-vitro study [33] showed that immune complexes consisting of anti-dsDNA, DNA and LDL augmented cholesterol accumulation in vascular smooth muscle cells and demonstrated cytotoxic activity. It was also reported that determination of antinuclear antibodies may be helpful also in the evaluation of coronary artery disease risk in subjects in whom no generalized autoimmune disease has been diagnosed [34].

Based on the positive results of SPECT and MDCT studies in a high proportion of stable SLE patients without cardiac symptoms, the question of final cardiac diagnosis arises. MDCT is characterized by very high specificity (95-97\%) and excellent negative predictive value (93-99\%) for stable coronary artery disease diagnosis [35]. The specificity of SPECT is estimated to be $70-75 \%$ [35]. Thus, an early stage of coronary artery disease may be diagnosed in patients with atherosclerotic plaques detected by MDCT in our study, as well as in patients with positive SPECT results, reflecting rather a "small vessel" type of the disease.

Our results discussed above may have valuable implications for the management of SLE patients in the future. The presence of atherosclerotic plaques and myocardial perfusion defects on SPECT study are strong predictors of 
death $[17,18,23-25]$. The mechanism of formation of these abnormalities, in which microthrombosis might play a major role, should direct our attention to thrombosis prevention in aPL-positive patients. It was reported that in asymptomatic aCL-positive patients thrombo-prophylaxis with aspirin or low-molecular-weight heparin during highrisk periods (surgery, immobilization) is effective in reducing thrombotic complications [36]. Among asymptomatic aCL-positive SLE patients, primary prophylaxis with aspirin and hydroxychloroquine also reduced the frequency of thrombotic events [37]. The value of antithrombotic treatment on perfusion abnormalities and formation of coronary calcifications and, consequently, on the prognosis of aCL-positive SLE patients should be addressed in large prospective clinical trials. It should be emphasized that the value of statin treatment in SLE patients free from clinical symptoms of cardiovascular disease has become an objective of ongoing randomized studies [38].

\section{Conclusion}

Coronary calcified plaques and myocardial perfusion defects are present in a high proportion of stable SLE patients without cardiac symptoms. Conventional risk factors for coronary artery disease as well as markers of an ongoing inflammation do not show an association with these pathologies. On the contrary, atherosclerosis is augmented in patients with increased levels of antiphospholipid antibodies of IgG class. It might be speculated that coronary artery calcifications and perfusion defects are a result of coronary artery microthrombosis induced by antiphospholipid antibodies.

Acknowledgments This study was supported by Grant No. N40201231/0460 from the Polish Ministry of Science and Higher Education.

Open Access This article is distributed under the terms of the Creative Commons Attribution Noncommercial License which permits any noncommercial use, distribution, and reproduction in any medium, provided the original author(s) and source are credited.

\section{References}

1. Bruce IN. "Not only... but also": factors that contribute to accelerated atherosclerosis and premature coronary heart disease in systemic lupus erythematosus. Rheumatology. 2005;44: 1492-502.

2. Pons-Estel GJ, Gonzales LA, Zhang J, Burgos PI, Reveille JD, Alarcon GS. Predictors of cardiovascular damage in patients with systemic lupus erythematosus: data from LUMINA (LXVIII), a multicenter US cohort. Rheumatology. 2009;48:817-22.
3. Wiik AS, Fritzler MJ. Laboratory tests in rheumatic disorders. In: Hochberg M, Silman A, Smolen J, Weinblatt M, Weisman M, editors. Rheumatology. Philadelphia: Mosby Elsevier; 2008. p. 219-32.

4. Del Papa N, Guidali L, Sala A, Buccellati C, Khamashta MA, Ichikawa K, et al. Endothelial cells as target for antiphospholipid antibodies. Human polyclonal and monoclonal anti $\beta 2$ glycoprotein-1 induced endothelial cell activation. Arthritis Rheum. 1997;40:551-61.

5. Pierangeli SS, Espinola RG, Liu XW, Harris EN. Thrombogenic effect of antiphospholipid antibodies are mediated by intracellular adhesion molecule-1, vascular cell adhesion molecule-1 and P-selectin. Circ Res. 2001;88:245-50.

6. Campbell AL, Pierangeli SS, Wellhausen S, Harris EN. Comparison of the effect of anticardiolipin antibodies from patients with antiphospholipid syndrome and with syphilis on platelet activation and aggregation. Thromb Haemost. 1995;73: 519-24.

7. Smirnov MD, Triplett DT, Comp PC, Esmon NL, Esmon CT. On the role of phosphatidylethanolamine in the inhibition of activated protein $\mathrm{C}$ activity by anti-phospholipid antibodies. J Clin Invest. 1995;95:309-16.

8. Miyakis S, Lockshin MD, Atsumi T, Branch DW, Brey RL, Cervera $\mathrm{R}$, et al. International consensus statement on an update of the classification criteria for definite anti phospholipid syndrome (APS). J Thromb Haemost. 2006;4:295-306.

9. Swadzba J, de Clerck LS, Stevens WJ, Bridts CH, van Cotton $\mathrm{KA}$, Musial J, et al. Anticardiolipin antibodies, anti- $\beta 2$-glycoprotein I, antiprothrombin antibodies and lupus anticoagulant in patients with systemic lupus erythematosus with a history of thrombosis. J Rheumatol. 1997;24:1710-5.

10. Smolen J, Weisman M. Connective tissue disorders. In: Hochberg M, Silman A, Smolen J, Weinblatt M, Weisman M, editors. Rheumatology. Philadelphia: Mosby Elsevier; 2008. p. 1205-485.

11. Smith EL, Shmerling RH. The American College of Rheumatology criteria for the classification of systemic lupus erythematosus: strengths, weaknesses, and opportunities for improvement. Lupus. 1999;8:586-95.

12. Permarheum SLEDAI Calculator: http://www.permarheum.org/ SLEDAI.html.

13. Agatson AS, Janowitz WR, Hildner FJ, Zusmer NR, Viamonte M Jr, Detrano R. Quantification of coronary artery calcium using ultrafast computed tomography. J Am Coll Cardiol. 1990;15:827-32.

14. Pengo V, Tripodi A, Reber G, Rand JH, Ortel TL, Galli M, et al. Update of the guidelines for lupus anticoagulant detection. Subcommittee on lupus anticoagulant/antiphospholipid antibody of the scientific and standarisation committee of the international society on thrombosis and haemostasis. J Thromb Haemost. 2009;7:1737-40.

15. Lin CC, Ding HJ, Chen YW, Wang JH, Ho ST, Kao A. Usefulness of technetium-99 m sestamibi myocardial perfusion SPECT in detection of cardiovascular involvement in patients with systemic lupus erythematosus or systemic sclerosis. Int J Cardiol. 2003;92:157-61.

16. Lin JJ, Hsu HB, Sun SS, Wang JJ, Ho ST, Kao CH. Single photon emission computed tomography of technetium-99 m tetrofosmin myocardial perfusion imaging in patients with systemic lupus erythematosus - a preliminary report. Jpn Heart J. 2003;44: 83-9.

17. Vanzetto G, Ormezzano O, Fagret D, Comet M, Denis B, Machecourt J. Long term additive prognostic value of thalium201 myocardial perfusion imaging over clinical and exercise stress test in low to intermediate risk patients: study in 1,137 patients with 6 year follow-up. Circulation. 1999;100:1521-7.

18. Hachamovitch R, Berman DS, Shaw LJ, Kiat H, Cohen I, Cabico JA, et al. Incremental prognostic value of myocardial perfusion 
single photon emission computed tomography for the prediction of cardiac death: differential stratification for risk of cardiac death and myocardial infarction. Circulation. 1998;98:190.

19. Petri M. The lupus anticoagulant is a risk factor for myocardial infarction (but not atherosclerosis): hopkins lupus cohort. Thromb Res. 2004;114:593-5.

20. Yiu KH, Wang S, Mok MY, Ooi GC, Khong PL, Mak KF, et al. Pattern of arterial calcification in patients with systemic lupus erythematosus. J Rheumatol. 2009;36:2212-7.

21. Kao AH, Wasko M, Krishnaswami S, Wagner J, Edmundowicz $\mathrm{D}$, Shaw $\mathrm{P}$, et al. C-reactive protein and coronary artery calcium in asymptomatic women with systemic lupus erythematosus or rheumatoid arthritis. Am J Cardiol. 2008;102:755-60.

22. Raggi P, Gongora M, Gopal A, Callister T, Budoff M, Shaw L. Coronary artery calcium to predict all-cause mortality in elderly men and women. J Am Coll Cardiol. 2008;52:17-23.

23. Chang SM, Nabi F, Xu J, Peterson LE, Achari A, Pratt CM, et al. The coronary artery calcium score and stress myocardial perfusion imaging provide independent and complementary prediction of cardiac risk. J Am Coll Cardiol. 2009;54:1872-82.

24. Polonsky TS, McClelland RL, Jorgensen NW, Bild DE, Burke GL, Guerci AD, et al. Coronary artery calcium score and risk classification for coronary heart disease prediction. JAMA. 2010;303:1610-6.

25. Uebleis C, Becker A, Griesshammer I, Cumming P, Becker C, Schmidt M, et al. Stable coronary artery disease: prognostic value of myocardial perfusion SPECT in relation to coronary calcium scoring-long-term follow-up. Radiology. 2009;252:682-90.

26. Farzaneh-Far A, Roman MJ, Lockshin MD, Devereux RB, Paget SA, Crow MK, et al. Relationship of antiphospholipid antibodies to cardiovascular manifestations of systemic lupus erythematosus. Arthritis Rheum. 2006;54:3918-25.

27. Gabrielli F, Alcini E, Prima MA, Lucifero A, Masala C. Cardiac involvement in connective tissue diseases and primary antiphospholipid syndrome: echocardiographic assessment and correlation with antiphospholipid antibodies. Acta Cardiol. 1996;51:425-39.

28. Cefle A, Inanc M, Sayarlioglu M, Kamali S, Gul A, Ocal L et al. Pulmonary hypertension in systemic lupus erythematosus: relationship with antiphospholipid antibodies and severe disease outcome. Rheumatol Int. 2011; 31:183-189.
29. Hasegawa EM, Caleiro MT, Fuller R, Carvalho JF. The frequency of anti-beta2-glycoprotein I antibodies is low and these antibodies are associated with pulmonary hypertension in mixed connective tissue disease. Lupus. 2009;18:618-21.

30. Roitt I. Autoimmunity and autoimmune diseases. In: Male D, Brostoff J, Roth DB, Roitt I, editors. Immunology. London: Mosby Elsevier; 2006.

31. Glueck CJ, Lang JE, Tracy T, Sieve-Smith L, Wang P. Evidence that anticardiolipin antibodies are independent risk factors for atherosclerotic vascular disease. Am J Cardiol. 1999;83:1490-4.

32. Le Tonqueze M, Salozhin K, Dueymes M, Piette JC, Kovalev V, Shoenfeld Y, et al. Role of $\beta 2$-glycoprotein I in the antiphospholipid antibody binding to endothelial cells. Lupus. 1995; 4:179-86.

33. Kabakov AE, Tertov VV, Saenko VA, Poverenny AM, Orekhow AN. The atherogenic effect of lupus sera: systemic lupus erythematosus-derived immune complexes stimulate the accumulation of cholesterol in cultured smooth muscle cells from human aorta. Clin Immunol Immunopathol. 1992;62:214-20.

34. Grainer DJ, Bethell HW. High titers of serum antinuclear antibodies, mostly directed against nucleolar antigens, are associated with the presence of coronary atherosclerosis. Ann Rheum Dis. 2002;61:110-4.

35. Fox K, Garcia M, Ardissino D, Buszman P, Camici P, et al. Guidelines on the management of stable angina pectoris. The task force on the management of stable angina pectoris of the European Society of Cardiology. Eur Heart J. 2006;27:1341-81.

36. Giron-Gonzales JA, Garcia del Rio E, Rodriguez C, RodriguezMartorell J, Serrano A. Antiphospholipid syndrome and asymptomatic carriers of antiphospholipid antibody: prospective analysis of 404 individuals. J Rheumatol. 2004;31:1560-7.

37. Wahl DG, Bounameaux H, de Moerloose P, Sarasin FP. Prophylactic antithrombotic therapy for patients with systemic lupus erythematosus with or without antiphospholipid antibodies: do the benefits outweigh the risks? A decision analysis. Arch Intern Med. 2000;160:2042-8.

38. Petri M, Kiani A, Post W, Christopher-Stine L, Madger L. Lupus atherosclerosis prevention study (LAPS). Ann Rheum Dis. 2011;70:760-5. 